\title{
The risk factors for brain metastases in patients with non-small cell lung cancer
}

\author{
Jun Hyeok Lim, Sang-Won Um \\ Division of Pulmonary and Critical Care Medicine, Department of Medicine, Samsung Medical Center, Sungkyunkwan University School of \\ Medicine, Seoul, South Korea \\ Correspondence to: Sang-Won Um, MD, MPH, PhD. Division of Pulmonary and Critical Care Medicine, Department of Medicine, Samsung Medical \\ Center, Sungkyunkwan University School of Medicine, 81 Irwon-ro, Gangnam-gu, Seoul, 06351, South Korea. Email: sangwonum@skku.edu. \\ Comment on: Waqar SN, Waqar SH, Trinkaus K, et al. Brain Metastases at Presentation in Patients With Non-Small Cell Lung Cancer. Am J Clin \\ Oncol 2018;41:36-40.
}

Submitted Sep 29, 2018. Accepted for publication Oct 11, 2018.

doi: $10.21037 / \mathrm{atm} .2018 .10 .27$

View this article at: http://dx.doi.org/10.21037/atm.2018.10.27

Non-small cell lung cancer (NSCLC) with brain metastasis is the most common central nervous system malignancy, accounting for as much as $20 \%$ of every brain metastasis case (1). The incidence of brain metastasis has been increasing due to improvements in the control of systemic extra-cranial disease and the widespread availability of imaging modalities such as magnetic resonance imaging (MRI), which has increased the detection of subclinical disease (2-4). NSCLC with brain metastasis often has a poor prognosis, with the median survival ranging between 4 and 6 months (5). Although brain MRIs are performed more often than ever before for the diagnosis of brain metastasis, this imaging procedure is still not performed in all patients with NSCLC. In recent guidelines, including both the National Comprehensive Cancer Network and American College of Chest Physicians, brain MRI was not recommended for asymptomatic stage I patients $(6,7)$. However, recent studies have revealed that brain metastasis can occur even in patients with early stage disease or in those without any symptoms $(8,9)$. There have been many studies about the risk factors of brain metastasis to predict the development of brain metastasis in patients with NSCLC. In addition, there have been several studies that have shown that clinical factors such as age, stage, and histology are associated with brain metastasis in NSCLC patients (10-14).

Waqar et al. published a study using the populationbased Surveillance, Epidemiology, and End Results (SEER) database on clinical risk factors to predict the development of brain metastasis (15). They searched the SEER-17 registry data for patients with NSCLC diagnosed over a 10-year period between January 1, 1988, and December 31,1997 . There was no record of brain metastasis in the SEER database, but patients who were referred to as "brain radiotherapy indicated" were considered to have brain metastases. Of the total 142,023 patients, 10,567 whose brain radiotherapy status was unknown were excluded. Among the remaining 131,456 patients, 10,963 (8.3\%) were "brain radiotherapy indicated". A multivariable analysis revealed that the following were significantly associated with brain radiotherapy use: younger age [odds ratio (OR), $0.65]$, adenocarcinoma histology (OR, 1.67), large cell or other histology (OR, 1.67), tumor size $>3 \mathrm{~cm}(\mathrm{OR}, 1.22$ in tumor $>3.1$ to $5 \mathrm{~cm}$ and 1.25 in tumor $>5 \mathrm{~cm}$ ), tumor grade III or IV (OR, 1.82 and 1.91), and N1, N2 or N3 nodal involvement (OR, 1.33, 2.24 and 2.39). The authors analyzed the clinical factors associated with the development of brain metastasis in NSCLC using a large-scale database and they also reported that the incidence of brain metastasis was $8.3 \%$ in patients with NSCLC, which has been infrequently mentioned in previous studies. However, there are limitations to this study. First, the data used in this study were collected 20 to 30 years ago and may not reflect the current situation. In addition, the incidence of brain metastasis may have been underestimated, since brain MRI was not commonly performed at that time. Second, there were no data on patients with brain metastases in the SEER database, and the authors used "brain radiotherapy indicated" as the surrogate maker for brain metastasis.

Recently, another study from the same authors was 
published to investigate a similar subject in patients with NSCLC based on the National Cancer Data Base registry between 2010 and 2012 (16). This more recent study improved upon the limitations of the previous study. In the later study, the authors used information about patients with brain metastases from a more recent database. In addition, a larger number of patients were included in the analysis. In the recent study, multivariable analysis revealed that a younger age, non-squamous histology, tumor size, tumor grade, and node-positive disease were clinical factors associated with brain metastasis. The incidence of brain metastasis was $10.4 \%$, which was higher than the previous study. Brain metastasis is common at initial presentation of primary lung cancer, and $91 \%$ of patients are diagnosed with brain metastasis within 1 year of initial diagnosis (17). Therefore, in patients with clinical factors that are thought to be associated with the development of brain metastasis (younger age, high tumor grade, non-squamous histology), brain MRI should be considered more actively at the time of diagnosis.

In addition to the clinical factors, various biomarkers have been reported to be associated with brain metastases (18-22). In patients with lung adenocarcinomas, the frequency of EGFR mutation was statistically higher for patients with brain metastases compared with epidermal growth factor receptor (EGFR) wild type (21). Brain metastases were more common in patients with echinoderm microtubule-associated protein-like 4 (EML4) and anaplastic lymphoma kinase (ALK)-positive compared with EGFR mutant patients (22). However, there were no statistically significant differences in the incidence of brain metastases based on ROS1, ALK, EGFR, KRAS, or BRAF mutation status in another study (23). Further studies are required to elucidate the biomarkers associated with brain metastases in the future.

\section{Acknowledgements}

None.

\section{Footnote}

Conflicts of Interest: The authors have no conflicts of interest to declare.

\section{References}

1. Barnholtz-Sloan JS, Sloan AE, Davis FG, et al. Incidence proportions of brain metastases in patients diagnosed (1973 to 2001) in the Metropolitan Detroit Cancer Surveillance System. J Clin Oncol 2004;22:2865-72.

2. Tabouret E, Chinot $\mathrm{O}$, Metellus $\mathrm{P}$, et al. Recent trends in epidemiology of brain metastases: an overview. Anticancer Res 2012;32:4655-62.

3. Villano JL, Durbin EB, Normandeau C, et al. Incidence of brain metastasis at initial presentation of lung cancer. Neuro Oncol 2015;17:122-8.

4. Smedby KE, Brandt L, Bäcklund M, et al. Brain metastases admissions in Sweden between 1987 and 2006. Br J Cancer 2009;101:1919.

5. Mehta MP, Rodrigus P, Terhaard C, et al. Survival and neurologic outcomes in a randomized trial of motexafin gadolinium and whole-brain radiation therapy in brain metastases. J Clin Oncol 2003;21:2529-36.

6. Silvestri GA, Gonzalez AV, Jantz MA, et al. Methods for staging non-small cell lung cancer: diagnosis and management of lung cancer: American College of Chest Physicians evidence-based clinical practice guidelines. Chest 2013;143:e211-50S.

7. Ettinger DS, Wood DE, Aisner DL, et al. Non-small cell lung cancer, version 5.2017, NCCN clinical practice guidelines in oncology. J Natl Compr Canc Netw 2017;15:504-35.

8. Shi AA, Digumarthy SR, Temel JS, et al. Does Initial Staging or Tumor Histology Better Identify Asymptomatic Brain Metastases in Patients with Non-small Cell Lung Cancer? J Thorac Oncol 2006;1:205-10.

9. Ando T, Kage H, Saito M, et al. Early stage non-small cell lung cancer patients need brain imaging regardless of symptoms. Int J Clin Oncol 2018:641-6.

10. Ceresoli GL, Reni M, Chiesa G, et al. Brain metastases in locally advanced nonsmall cell lung carcinoma after multimodality treatment: risk factors analysis. Cancer 2002;95:605-12.

11. Mujoomdar A, Austin JH, Malhotra R, et al. Clinical predictors of metastatic disease to the brain from nonsmall cell lung carcinoma: primary tumor size, cell type, and lymph node metastases. Radiology 2007;242:882-8.

12. Wang SY, Ye X, Ou W, et al. Risk of cerebral metastases for postoperative locally advanced non-small-cell lung cancer. Lung Cancer 2009;64:238-43.

13. Won YW, Joo J, Yun T, et al. A nomogram to predict brain metastasis as the first relapse in curatively resected non-small cell lung cancer patients. Lung Cancer 2015;88:201-7.

14. Lee H, Jeong SH, Jeong BH, et al. Incidence of brain 
metastasis at the initial diagnosis of lung squamous cell carcinoma on the basis of stage, excluding brain metastasis. J Thorac Oncol 2016;11:426-31.

15. Waqar SN, Waqar SH, Trinkaus K, et al. Brain Metastases at Presentation in Patients With Non-Small Cell Lung Cancer. Am J Clin Oncol 2018;41:36-40.

16. Waqar SN, Samson PP, Robinson CG, et al. Non-smallcell Lung Cancer With Brain Metastasis at Presentation. Clin lung cancer 2018;19:e373-9.

17. Schouten LJ, Rutten J, Huveneers HA, et al. Incidence of brain metastases in a cohort of patients with carcinoma of the breast, colon, kidney, and lung and melanoma. Cancer 2002;94:2698-705.

18. Grinberg-Rashi H, Ofek E, Perelman M, et al. The expression of three genes in primary non-small cell lung cancer is associated with metastatic spread to the brain. Clin Cancer Res 2009; 15:1755-61.

19. Breindel JL, Haskins JW, Cowell EP, et al. EGF Receptor activates MET through MAP kinases to enhance non-

Cite this article as: $\mathrm{Lim} \mathrm{JH}, \mathrm{Um} \mathrm{SW}$. The risk factors for brain metastases in patients with non-small cell lung cancer. Ann Transl Med 2018;6(Suppl 1):S66. doi: 10.21037/atm.2018.10.27 small cell lung carcinoma invasion and brain metastasis. Cancer Res 2013;73:5053-65.

20. Li Q, Yang J, Yu Q, et al. Associations between singlenucleotide polymorphisms in the PI3K-PTEN-AKTmTOR pathway and increased risk of brain metastasis in patients with non-small cell lung cancer. Clin Cancer Res 2013;19:6252-60.

21. Shin DY, Kim CH, Park S, et al. EGFR mutation and brain metastasis in pulmonary adenocarcinomas. J Thorac Oncol 2014;9:195-9.

22. Kang HJ, Lim HJ, Park JS, et al. Comparison of clinical characteristics between patients with ALK-positive and EGFR-positive lung adenocarcinoma. Respir Med 2014;108:388-94.

23. Patil T, Smith DE, Bunn PA, et al. The Incidence of Brain Metastases in Stage IV ROS1-Rearranged NonSmall Cell Lung Cancer and Rate of Central Nervous System Progression on Crizotinib. J Thorac Oncol 2018;13:1717-26. 